Editorial

\title{
E-Government and Smart Cities: Theoretical Reflections and Case Studies
}

\author{
Peter Mechant ${ }^{1, *}$ and Nils Walravens ${ }^{2}$ \\ ${ }^{1}$ Research Group for Media, Innovation and Communication Technologies, Ghent University, 9000 Ghent, Belgium; \\ E-Mail: peter.mechant@ugent.be \\ ${ }^{2}$ Centre for Studies on Media, Information and Technology, Vrije Universiteit Brussel, 1050 Brussels, Belgium; \\ E-Mail: nils.walravens@vub.be \\ * Corresponding author
}

Submitted: 29 November 2018 | Published: 21 December 2018

\begin{abstract}
This editorial introduces the thematic issue on "E-Government and Smart Cities: Theoretical Reflections and Case Studies" and presents five articles and one commentary related to e-government and smart cities. All contributions take a use-case driven research approach to investigate, discuss and comment (on) overarching themes such as data, governance and participation which are inherently linked to the concepts of e-government and smart cities.
\end{abstract}

\section{Keywords}

e-government; government communication; government services; participation; smart city; smart governance

\section{Issue}

This editorial is part of the issue "E-Government and Smart Cities: Theoretical Reflections and Case Studies", edited by Peter Mechant (Ghent University, Belgium) and Nils Walravens (Vrije Universiteit Brussel, Belgium).

(C) 2018 by the authors; licensee Cogitatio (Lisbon, Portugal). This article is licensed under a Creative Commons Attribution 4.0 International License (CC BY).

\section{Background}

Today, the concepts of e-government and smart city are increasingly used to refer to one another and have started to converge. While e-government was introduced under the flag of better service delivery by focusing on internal processes and the use of information and communications technologies (ICTs) by administrations, the smart city concept nowadays builds on this as a way to foster innovation by collecting, processing, integrating and using data on a larger scale than ever before. This supposedly leads to better-informed decision making and high quality services, but assumes far more complex partnerships with very diverse stakeholders, such as large and small companies, civil society, academia, individual citizens and so on (triple, quadruple, and quintuple helix models).

While the concept of "smart city" is adopted by many cities as a strategic priority that recognizes the growing importance of digital technologies (software as well as hardware), at the same time the phrase is used as a mar- keting concept to envision a city of the future. While very popular, the smart city concept remains elusive. It is often unclear to city administrations how the concept should be interpreted (if there even is a "right" way to do so) and what it can mean in practice. However, most seem to agree a smart city should focus on collaborating with diverse stakeholders, using technology as an enabler to achieve better and more efficient services to citizens.

While the offer of e-government services has increased substantially in the last decade-both in numbers and in complexity-statistics on the demand side (i.e., the actual use), however, show less impressive results. In 2014, usage of e-government services increased to $46 \%$ of EU citizens, but more than half dropped out after first use (United Nations, 2014, p. 162). Hence, in order to develop and deliver e-government services that are useful, easy to use, accessible and trustworthy, "efforts to provide e-government need to go hand in hand with efforts to increase demand" (United Nations, 2014, p. 144). 
Given the focus of both e-government and the smart city concept on service delivery and optimisation of processes to achieve this, the terms have become increasingly intertwined. This also means looking at the problem from a more interdisciplinary perspective than ever before. This issue of Media and Communication delves deeper in the converging concepts of e-government and smart city, taking a critical approach and a perspective from communication-related disciplines and government studies. It tries to bring together research on this topic that follows a use-case driven research approach. Although results from case studies are difficult to generalise from local settings to a wider context or population, they do provide a rich source of qualitative information and make complex issues accessible and interesting to both an expert and non-expert audience. Moreover, they can capture what Hodkinson and Hodkinson call "lived reality" (2001, p. 3), or the complexities of contexts and conditions. A case study approach allows presenting particular instances of the intertwining and converging e-government and smart city practices and policies with an explorative purpose (Denscombe, 2017).

\section{Contributions}

Three main overarching themes can be discerned throughout this issue that are inherently linked to the intertwined concepts of "e-government" and "smart city": data, governance and participation.

The first theme, data, is an aspect that is deemed of particular importance to "smarter" forms of governance. The idea is that governments are currently "sitting" on a wealth of information related to divergent aspects of life in the city, but that this data is neither publicly available, nor easily interpretable. This has sparked a movement to encourage the opening of datasets in a structured and machine-readable way, under the "open data" moniker, which has gained significant traction across local and national governments. This theme is covered by Buyle et al. (2018) more specifically, in the article titled "'Technology Readiness and Acceptance Model' as a Predictor for the Use Intention of Data Standards in Smart Cities" they consider the relationship between individual characteristics of decision makers and their intention to use data standards. Using the Technology Readiness and Acceptance Model (TRAM) in an online survey $(n=205)$ they conclude that respondents who score high on innovativeness have a higher intention to use data standards. However, their results also show that personality characteristics as described in the TRAM-model are not significant predictors for the perceived usefulness and perceived ease of use of data standards (Buyle et al., 2018). In the article on channel choice determinants of (digital) government communication the authors study among others the perception towards the evolving digitization of communication and services and the "datafication" of e-government services. Laenens, Van den Broeck and Mariën (2018) conducted focus groups with a het- erogeneous panel of over 80 citizens, ranging from nonusers of digital technologies to high level users, to study their choice of communication channel and their perception towards the evolving digitization of communication and services in specific related to spatial planning in Flanders (Belgium). Their results show that citizens opt for local communication channels when interacting with local, regional, and national governments, and that they prefer to be personally informed when the communicated message has a direct impact on them. It also highlights how more vulnerable digital profiles consider the transition to digital communication by default as problematic (Laenens et al., 2018).

The second theme, governance, emphasizes the shifts as the role of the private sector becomes opaquer and (local) governments explore new financing and business models. Developments in the study of new forms of governance and social innovation have focused on the changing roles of public officials in their interactions with citizens and models are proposed in which public officials show higher responsiveness to citizens and promote active citizenship. Indeed, central to the emerging paradigm of governance is that public services should be a co-creation between governments, businesses, nonprofit organisations and citizens. As early as the 1970s, Nobel Prize winner Elinor Ostrom (1972) demonstrated that government departments that engaged with their environments functioned much better than those that did not. In this issue, governance is taken on by Shenja van der Graaf (2018) who uses the case of Waze to explore the current "place" of e-government in realizing public value in the context of a complex platform-based urban ecosystem encompassing private and public organisations and citizens. She argues that "mainstreaming" of e-government practices demands cities and governments to reconsider their own role in "city making" so as to achieve meaningful public oversight.

A third, main overarching theme in this issue is participation, highlighting how local governments are exploring new forms of collaboration and cooperation with citizens that are enabled by technology, while facing risks related to inclusion, media literacy and privacy. Often participatory design-a diverse collection of principles and practices that facilitate the direct involvement of users in the design of things, services, spaces and technologies-is adopted to empower those citizens who are affected by the design. The first contribution to this theme, and opening piece of this special issue, is by Beth Simone Noveck (2018), who considers new participatory law and policy making platforms in "Forging Smarter Cities through CrowdLaw". She discusses cases that leverage technology to tap into diverse sources of opinions and expertise such as the "vTaiwan" experimental e-consultation platform, the open source platform and process "Better Reykjavik" and "TransGov", a platform created in 2014 to help Ghanaian citizens monitor the progress of local development projects empowering them to hold government accountable. The next 
contribution addressing the theme of participation situates in the city of Glasgow and was authored by Webster and Leleux (2018). Their article provides insights into the ways in which its citizens and local communities have been engaged in governance processes. It shows that this engagement has taken place via traditional and innovative smart city technologies, and in particular in relation to policy formulation, service design and delivery. It also demonstrates that the co-creation of governance is shaped by vested interests and that engagement is fragmented and partial. However, the article argues that new technologies, social media and shared learning opportunities offer innovative new ways for some citizens to influence local governance and that an evolution to smart governance is possible given that the key ingredients of political leadership, new financial resources, technological expertise and citizen and community engagement are present. The third article in this theme investigates the impact of user participation methods on e-government projects by means of a case-study of the city of La Louvière. Simonofski, Vanderose, Clarinva and Snoeck (2018) studied this city during more than one year following action research best practices and describe the challenges and benefits the city experienced with participation methods. In their article they suggest a participation method matrix for a participatory e-government project and discuss the similarities and differences, as experienced by practitioners, between the converging concepts of e-government and smart cities.

\section{Conclusion}

The aim of this issue was to bring together contributions on e-government in a smart city context from a wide variety of communication-related disciplines, government studies and related fields. We hope that this thematic issue of Media and Communication will contribute and stimulate further academic discussions and explorations of how data, governance and participation are inherently linked to the converging concepts of "e-government" and "smart city" and hope you enjoy reading it as much as we have.

\section{Acknowledgements}

We would like to thank the contributors to this thematic issue for their commitment, the reviewers for providing invaluable feedback, and the editorial office for guidance and support. This project has received funding from the European Union's Horizon 2020 research and innovation programme under grant agreement No. 726755.

\section{Conflict of Interests}

The authors declare no conflict of interests.

\section{References}

Buyle, R., Van Compernolle, M., Vlassenroot, E., \& Mechant, P. (2018). 'Technology readiness and acceptance model' as a predictor for the use intention of data standards in smart cities. Media and Communication, 6(4), 127-139.

Denscombe, M. (2017). The good research guide. New York, NY: Open University Press.

Hodkinson, P., \& Hodkinson, H. (2001). The strengths and limitations of case study research. Paper presented at the Learning and Skills Development Agency Conference-Making an Impact on Policy and Practice, Cambridge. Retrieved from http://education. exeter.ac.uk/tlc/docs/publications/LE_PH_PUB_05. 12.01.rtf

Laenens, W., Van den Broeck, W., \& Mariën, I. (2018). Channel choice determinants of (digital) government communication: A case study of spatial planning in Flanders. Media and Communication, 6(4), 140-152.

Noveck, B. S. (2018). Forging smarter cities through CrowdLaw. Media and Communication, 6(4), 123-126.

Ostrom, E. (1972). Metropolitan reform: Propositions derived from two traditions. Social Science Quarterly, 53(3), 474-493.

Simonofski, A., Vanderose, B., Clarinval, A., \& Snoeck, M. (2018). The impact of smart governance on egovernment projects: The case of La Louvière, Belgium. Media and Communication, 6(4), 175-186.

United Nations. (2014). E-government for the future we want. New York, NY: United Nations. Retrieved from https://publicadministration.un.org/egovkb/Portals/ egovkb/Documents/un/2014-Survey/E-Gov_Com plete_Survey-2014.pdf

Van der Graaf, S. (2018). In Waze we trust: Algorithmic governance of the public sphere. Media and Communication, 6(4), 153-162.

Webster, C. W. R., \& Leleux, C. (2018). Delivering smart governance in a future city: The case of Glasgow. Media and Communication, 6(4), 163-174.

\section{About the Authors}

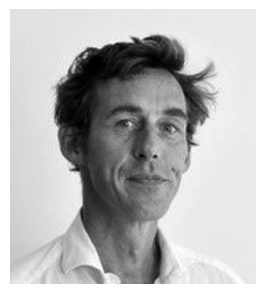

Peter Mechant is Senior Researcher at Research Group for Media, Innovation and Communication Technologies (imec-mict-Ghent University: www.mict.be) working on projects related to e-government, smart cities and online communities. He holds a PhD in Communication Sciences from Ghent University (2012) which focused on interactivity in a Web 2.0 context and posited a conceptual framework to explore how software enables and constrains agency and engagement. 


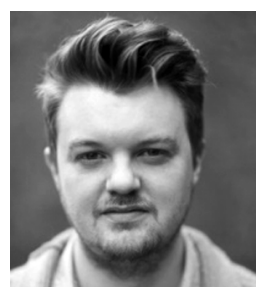

Nils Walravens is Senior Researcher at the Centre for Studies on Media, Information and Technology (imec-SMIT-VUB: smit.vub.ac.be), working on open data and smart cities. Nils holds a PhD in Communication Sciences from the Vrije Universiteit Brussel (2016) which focused on business models for smart cities, creating public value and the role of city governments in creating "smart" solutions. 